\title{
Modelling the long term dispersion of radioactive liquid effluent and dose from marine pathways using a grid model
}

\author{
P. Gleizon, P. McDonald and S.E. Bryan \\ Westlakes Scientific Consulting Ltd., The Princess Royal Building, Westlakes Science \& \\ Technology Park, Moor Row, Cumbria CA24 3LN, UK
}

\begin{abstract}
A grid model was developed to combine small-scale grid resolution and long-term predictions of radionuclide dispersion in shallow seas. A predictor-corrector algorithm ensures an unconditional stability of the model. Four modules calculate the concentration of suspended sediments, the dispersion of radionuclides in the marine environment, and the doses to members of the public and marine biota. The model was applied to the dispersion of liquid effluent in the Irish Sea from the Sellafield nuclear reprocessing plant, Cumbria (UK). The concentration factors and partition coefficients have been calibrated for biota species and local conditions. The validation against environmental samples for twenty-two radionuclides shows a good agreement between predicted and measured values.
\end{abstract}

\section{INTRODUCTION}

The dispersion of long-lived contaminants in the marine environment presents a challenge to numerical modelling. Their residence time in the environment requires long term modelling periods, most often on a large scale. In order to keep the computing time at a reasonable level and avoid computing instabilities, compartmental models are usually preferred for modelling contaminant transport for a long-term period, typically beyond two decades.

In compartmental models (e.g. [1]), the contaminant concentration is calculated in each compartment. The exchanges between the compartments are defined by transfer coefficients that represent the fluxes of water, salinity and suspended particulate matter (SPM). The compartmental models also represent the exchange between the water column and the bed sediment. Due to the relatively low computational demand of these models, more complex processes can be simulated, such as the migration of contaminants in bed sediment by burial or bioturbation, or a full representation of radionuclide decay chains. However, compartmental models have a crude resolution because they assume a uniform distribution within compartments and instantaneous mixing.

Grid models (e.g. [2]) are more refined but also more computationally demanding, which limits their spatial and temporal coverage. Some cases however can require an evaluation of the long-term impact of anthropogenic contamination over relatively small areas, such as the natural preservation areas, where both compartmental and grid models may prove inadequate.

The grid model presented here uses a specific algorithm that solves explicitly the driving equations on a fine mesh grid interval $(2 \mathrm{~km})$ with a large time step (one year) with an unconditional stability. The model design and functionality are presented in the next section and its application to the Irish Sea is discussed.

\section{MODEL DESCRIPTION AND FUNCTIONALITY}

The two-dimensional depth-averaged long-term grid model MARISA was originally developed to simulate the dispersion of the radionuclides in the Irish Sea over a long period (100 years) from liquid discharge of nuclear installations [3]. The grid, which initially covered only the Eastern Irish Sea, was 
extended to the entire Irish Sea and refined to a regular 2-km interval. The model currently comprises four modules that calculate: the SPM concentration; the radionuclide concentration in seawater, SPM and bed sediment; the dose to critical groups from marine pathways and the dose to marine organisms.

The radionuclide dispersion is calculated by finite difference using an explicit scheme with a time interval of one year. The residual flow field used for the advection was derived from a one-year hydrodynamic simulation of the Irish Sea, including typical wind forcing data, using the commercially available model MIKE21 [4], and averaged over a year to extract the residual velocity. The SPM concentration field is deduced from the bed sediment distribution and the residual flow field, assuming that for a long time scale, only the mud in bed sediment contributes to the net resuspension, as larger particles, such as sand, are eroded and deposited over shorter periods.

Using this residual velocity and SPM distribution field, the activity concentration is calculated for each sorption phase, allowing transfer between seawater, SPM and seabed sediment in addition to the advective and dispersive processes.

The equations are solved using a Backward Differentiation Formula, which is the combination of a complex predictor-corrector method and a multi-value method [5]. A 'predictor' vector containing derivatives of the Taylor series expansion of the solution being sought, are used to obtain a first guess of the actual solution. Newton's method is then used to iterate the predictor to provide a closer estimate of the solution. The order of the method is defined by truncation errors, involving an error tolerance level, to optimise the stability and the concentration gradients to the time steps. This method, although computationally demanding, is unconditionally stable even for large time steps, and limits the numerical diffusion.

The activity concentration of ${ }^{137} \mathrm{Cs}$ in seawater was originally used to validate the model predictions. Further validations were done with ${ }^{90} \mathrm{Sr},{ }^{99} \mathrm{Tc},{ }^{106} \mathrm{Ru}, \mathrm{Pu}(\alpha)$ and ${ }^{241} \mathrm{Am}$ using environmental data [6]. Currently, the model is calibrated for 22 radionuclides including two daughter products $\left({ }^{95} \mathrm{Nb}\right.$ and $\left.{ }^{241} \mathrm{Am}\right)$. The SPM concentration predictions were validated both qualitatively using remote sensing analysis, and quantitatively from water sample analysis [7].

The calculation of the radionuclide activity concentration assumes equilibrium between the dissolved, suspended and deposited phases at each time step:

$$
\begin{aligned}
\frac{\partial \mathrm{hc}_{1}}{\partial \mathrm{t}} & =-\vec{\nabla} \cdot\left(\mathrm{hum}_{1}\right)+\vec{\nabla} \cdot\left(\mathrm{hK} \vec{\nabla} \mathrm{c}_{1}\right)-\left(\frac{\alpha_{\mathrm{b}} \mathrm{K}_{\mathrm{D}}}{\rho}\left(\mathrm{P}+\frac{\mathrm{l}_{\mathrm{s}} \rho_{\mathrm{s}} \phi}{\lambda}\right)+\delta\right) \mathrm{hc}_{1}+\alpha \mathrm{hc}_{2}+\alpha_{\mathrm{b}} \mathrm{hc}_{3} \\
\frac{\partial \mathrm{hc}_{2}}{\partial \mathrm{t}} & =-\vec{\nabla} \cdot\left(\mathrm{huc}_{2}\right)+\vec{\nabla} \cdot\left(\mathrm{hK} \vec{\nabla} \mathrm{c}_{2}\right)+\frac{\alpha \mathrm{K}_{\mathrm{D}} \mathrm{P}}{\rho} \mathrm{hc}_{1}-\left(\alpha+\frac{\mathrm{w}_{\mathrm{s}}}{\mathrm{h}}+\delta\right) \mathrm{hc}_{2}+\frac{\mathrm{w}_{\mathrm{s}} \mathrm{P}}{\lambda \phi \rho_{\mathrm{s}}} \mathrm{hc}_{3}+\sigma \\
\frac{\partial \mathrm{hc}_{3}}{\partial \mathrm{t}} & =\alpha_{\mathrm{b}} \mathrm{K}_{\mathrm{D}} \frac{1_{\mathrm{s}} \rho_{\mathrm{s}} \phi}{\lambda \rho} \mathrm{hc}_{1}+\mathrm{w}_{\mathrm{s}} \mathrm{c}_{2}-\left(\alpha_{\mathrm{b}}+\frac{\mathrm{w}_{\mathrm{s}} \mathrm{P}}{\lambda \phi \rho_{\mathrm{s}}}+\delta\right) \mathrm{c}_{3}
\end{aligned}
$$

In the equation (2) $c_{1}, c_{2}$ and $c_{3}$ represents the activity concentration in dissolved, suspended and deposited phases respectively (full explanation of equation (2) notation given after list of references). Different desorption rates are used for bed sediment and suspended sediment in order to take into account different conditions of light, temperature and aggregation [8]. This appears all the more relevant for the model that redissolution from bed sediments influences mainly the near-bed seawater, while desorption from suspended sediment occurs throughout the water column and therefore is likely to have a stronger influence on the depth averaged level of activity in the dissolved phase.

Transfer coefficients are used to calculate the transfer of activity from seawater to marine organisms and coastal sediments for the purpose of dose assessment to critical groups. These coefficients were calibrated against environmental samples reported by [9].

More recently, the allometric methodology was applied within MARISA to calculate the dose to marine biota by assimilating the organisms to ellipsoids [10]. The dose per unit concentration is defined for three emission types (low beta, beta + photon, and alpha) and takes into account the type of habitat of the biota following the method presented by Vives i Batlle et al. [10]. 


\section{RESULTS AND DISCUSSION}

Simulations were performed for historical liquid discharges of twenty-two radionuclides from the Sellafield nuclear installation in United Kingdom [11]. Figure 1 shows the predicted distribution of ${ }^{137} \mathrm{Cs}$ activity concentration in seawater and in bed sediment in 2000 . The general circulation in the Irish Sea is cyclonic with a net inflow in the St George Channel (south), and outflow in the North Channel (north). The pattern shown by the activity concentration reflects this circulation and is in agreement with Jefferies and Steele [12] observations indicating higher concentrations in the Northern Irish Sea than in the Southern Irish Sea. The distribution of activity in bed sediment presents a more complex and significantly different pattern, which mainly shows an affinity with the percentage of fine grain sediments on the seabed.

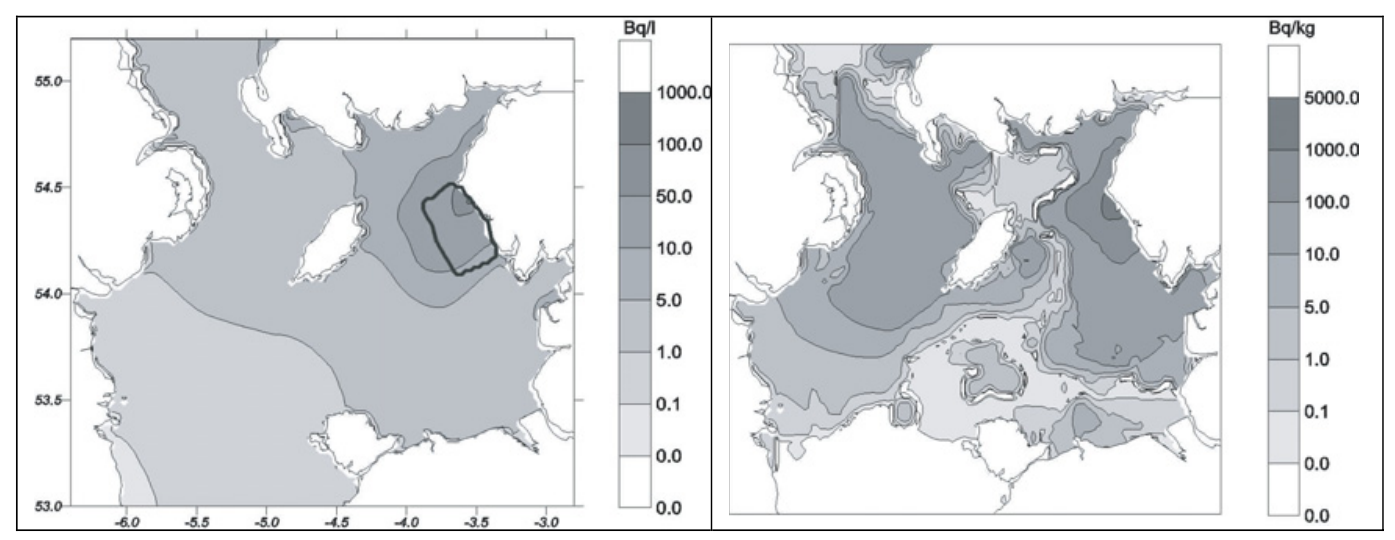

Figure 1. Predicted activity concentration of ${ }^{137} \mathrm{Cs}$ in seawater (left) and bed sediment (right) in 2000.

To estimate the uptake of activity by marine species, the activity concentration in seawater and sediment is averaged over the area where these species are located. Levels of activity have been monitored for decades for some species in targeted areas, as for instance in cod and plaice near the northwest coast of England (fishing area delineated in left figure 1). Figure 2 compares the predictions with the measured ${ }^{137} \mathrm{Cs}$ activity concentration in fish from this area.

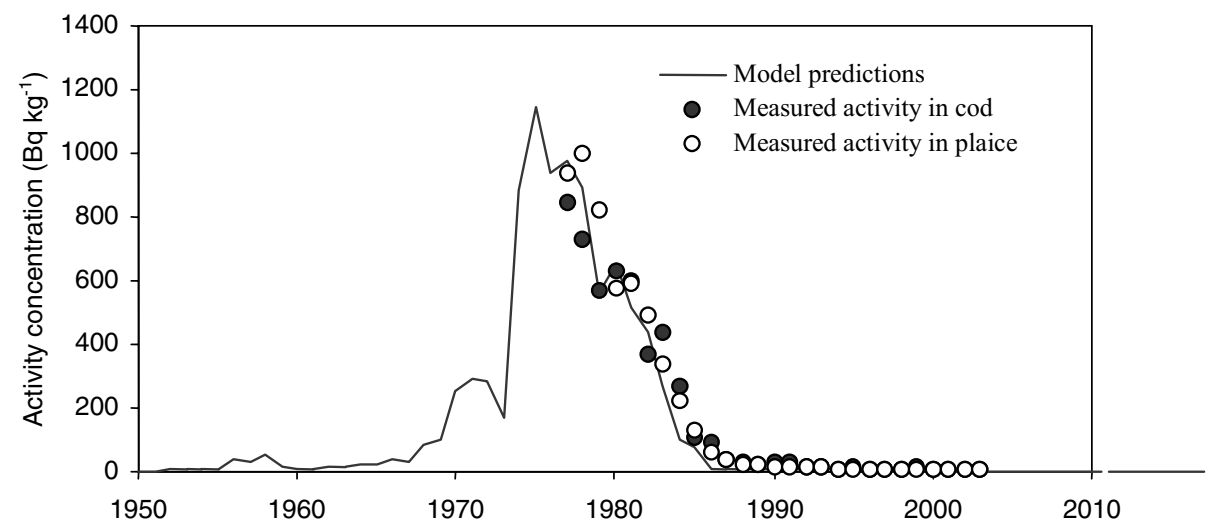

Figure 2. Activity concentration of ${ }^{137} \mathrm{Cs}$ in fish from the eastern Irish Sea. 
The model predictions are also in good agreement with measured activity concentration in other marine biota and for other radionuclides. Cobalt-60 was discharged at a lower level, with two peak discharge periods separated by a low discharge period in the early 90s. The measured and predicted activities in winkles reflect that trend (Figure 3). Comparatively, ${ }^{241} \mathrm{Am}$ shows a high peak discharge in the early 70s followed by low discharge periods. During periods of low discharges, the strong binding affinity of ${ }^{241} \mathrm{Am}$ to sediment maintains a level of activity in seawater and marine organism from past discharges due to the remobilisation of particles. For instance in Figure 4, both model predictions and data show low level activity in mussels tailing off at approximately $15 \mathrm{~Bq} \cdot \mathrm{kg}^{-1}$ (wet weight) although ${ }^{241}$ Am discharged activity is comparatively very low.

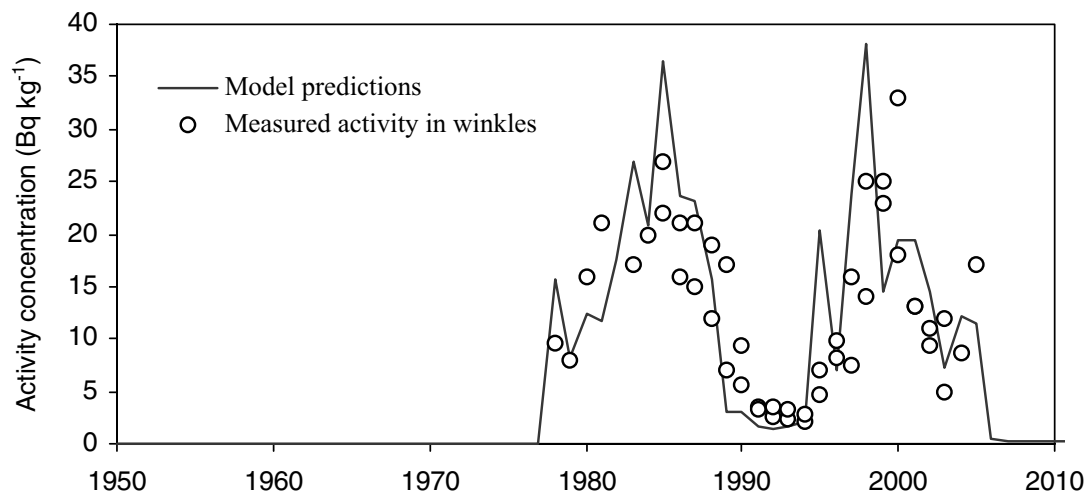

Figure 3. Activity concentration of ${ }^{60} \mathrm{Co}$ in winkles from the eastern Irish Sea.

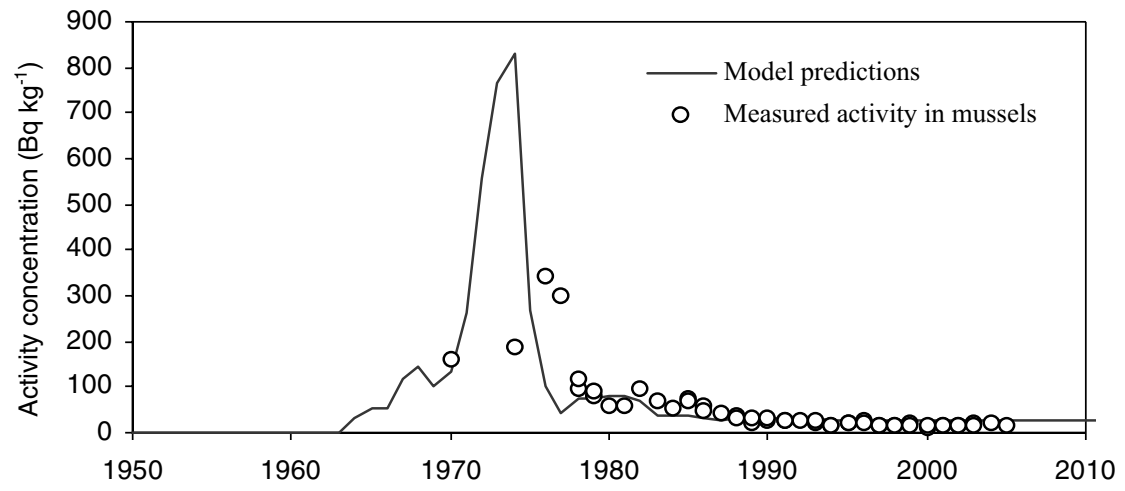

Figure 4. Activity concentration of ${ }^{241} \mathrm{Am}$ in mussels from the eastern Irish Sea.

Technetium-99 is predominant in the dissolved phase. Figure 5 shows two periods of high activity concentration in crabs separated by a period of low activity, which mirror the discharges profile. The model replicates well the variations of the measured activity although the yearly time steps used in the simulation cannot take into account the sub-annual variations. Moreover, the model assumes that the equilibrium is reached at each time step between seawater, sediment and marine organisms. The bioaccumulation of radionuclides in some organisms can result in significant lag effects. For instance Olsen and Vives i Batlle [13] predicted a lag effect of 10 months due to the bioaccumulation of ${ }^{99} \mathrm{Tc}$ in lobsters. In the latest years, ${ }^{99} \mathrm{Tc}$ discharged activity has reduced considerably making this lag effect 


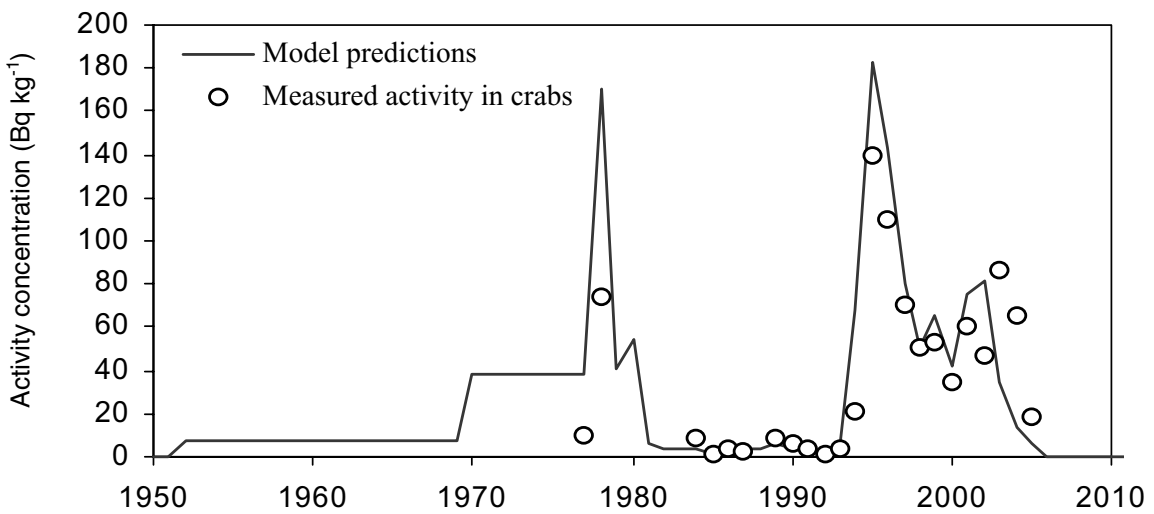

Figure 5. Activity concentration of ${ }^{99} \mathrm{Tc}$ in crabs from the eastern Irish Sea.

more apparent (Figure 5). A biokinetic modelling approach is currently being developed at Westlakes Scientific Consulting to refine the predictions in the radioactivity intake by marine biota [14].

Similar activity concentrations in the various marine organisms were estimated using the allometric methodology. This latter methodology is more flexible as it also takes into account the different habitat types, sizes and shapes of the species often classified in the same category, such as crustaceans for lobsters and shrimps.

As shown in figure 1, the distribution of activity concentration in seabed sediment reveals a complex variability. Depending on their habitat, marine species can intake more or less activity from seawater or seabed sediment. Grid models offer a fine resolution to represent such variability in distribution and have more flexibility in defining specific fishing areas.

Uncertainties inherent to sediment transport and contaminant dispersion are more significant for long-term modelling, as the solutions tend to diverge more for longer periods of time. Other types of uncertainties come from possible annual variability in the residual flow field due to differences in meteorological conditions or riverine discharges, or from the migration of marine species that can influence their intake of activity from the natural background.

\section{NOTATIONS}

$\mathrm{h}=$ mean depth of water

$\mathrm{K}=$ dispersion coefficient

$\overrightarrow{\mathrm{u}}=$ vector of the residual velocity

$\alpha, \alpha_{\mathrm{b}}=$ desorption rates from suspended and deposited sediments

$\rho, \rho_{\mathrm{s}}=$ density of seawater and sediment

$\mathrm{K}_{\mathrm{D}}=$ partition coefficient

$\mathrm{P}=$ suspended sediment concentration

$\mathrm{w}_{\mathrm{s}}=$ suspended sediment settling velocity

$1_{\mathrm{s}}, \lambda=$ desorption and mixing depths in sediment

$\phi=$ percentage of fine grained sediment

$\delta=$ decay rate

$\sigma=$ activity input rate from a source

\section{Acknowledgments}

WSC would like to acknowledge the support from Sellafield Ltd, formerly BNFL, when performing this work. 


\section{References}

[1] Iosjpe M., J. Brown and P. Strand, A modified approach for box modelling of radiological consequences from releases into the marine environment, Journal of Environmental Radioactivity 60 (2002) 297-322.

[2] Abril J.M. and M. García León, A 2D 4-phases marine dispersion model for nonconservative radionuclides. Part I: conceptual and computational model, Journal of Environmental Radioactivity 20 (1993) 71-88.

[3] Howorth J. and C.R. Kirby, Studies of environmental radioactivity in Cumbria. Part 11: modelling the dispersion of radionuclides in the Irish Sea. Environmental and Medical Sciences Division, Harwell Laboratory, AERE-R11734 (1988).

[4] DHI, MIKE21 Coastal hydraulics and oceanography hydrodynamics module release 2.6. Danish Hydraulics Institute (1996).

[5] Gear C.W., Numerical initial value problems in ordinary differential equations. Prentice-Hall, NJ (1971).

[6] MAFF, Aquatic environment monitoring report Radioactivity in surface and coastal waters of the British Isles. Directorate of Fisheries Research, Lowestoft (1967-1994).

[7] Smith C.N., T.H. Stewart and P. McDonald, Results from an intensive measurement programme for suspended particulate matter in the region of the Irish Sea between Anglesey and the Isle of Man, Continental Shelf Research 23 (2003) 1005-1018.

[8] McCubbin D., K.S. Leonard and H.S. Emerson, The role of thermal and photochemical reactions upon the remobilisation of $\mathrm{Pu}$ from an Irish Sea sediment, Journal of Environmental Radioactivity 44 (1999) 253-273.

[9] FSA, Radioactivity in food and the environment, 1997-2004. Food Standard Agency, Environment Agency, Scottish Environment Protection Agency, Environment \& Heritage Service, RIFE 1-11 (1996-2005).

[10] Vives i Batlle J., S.R. Jones and J.M. Gómez-Ros, A method for calculation of dose per unit concentration values for aquatic biota. Journal of Radiological Protection 24 (2004) a1-a2.

[11] Gray J., S.R. Jones and A.D. Smith, Discharges to the environment from the Sellafield site, Journal of Radiological Protection 15 (2) (1995) 99-131.

[12] Jefferies D.F. and A.K. Steele, Observed and predicted concentrations of Caesium-137 in Seawater of the Irish Sea 1970-1985, Journal of Environmental Radioactivity 10 (1989) 173-189.

[13] Olsen Y.S. and J. Vives i Batlle, A model for the bioaccumulation of ${ }^{99}$ Tc in lobsters (Homarus gammarus) from the West Cumbria coast, Journal of Environmental Radioactivity 67 (2003) 219-233.

[14] Vives i Batlle, J., R.C. Wilson, S.J. Watts, S.R. Jones, P. McDonald and S. Vives-Lynch, Dynamic model for the assessment of radiological exposure to marine biota, Journal of Environmental Radioactivity (accepted for publication). 